\title{
Erratum to: Shallow-water solutions for gravity currents in non-rectangular cross-area channels with stratified ambient
}

\section{Marius Ungarish}

Published online: 24 February 2015

(C) Springer Science+Business Media Dordrecht 2015

\section{Erratum to: Environ Fluid Mech DOI 10.1007/s10652-014-9383-y}

In the third frames of Figs. 9, 11 and 14, plot of $h_{N}$ vs. t, the correct values of $S$ are: 1, 0.75, 0.5 and 0 , for the upper (black) line, downward (red, blue, green). The corrected figure frames are given below.

The online version of the original article can be found under doi:10.1007/s10652-014-9383-y.

M. Ungarish $(\square)$

Department of Computer Science, Technion, 32000 Haifa, Israel

e-mail: unga@cs.technion.ac.il 
Fig. 9 Third frame

Fig. 11 Third frame

Fig. 14 Third frame
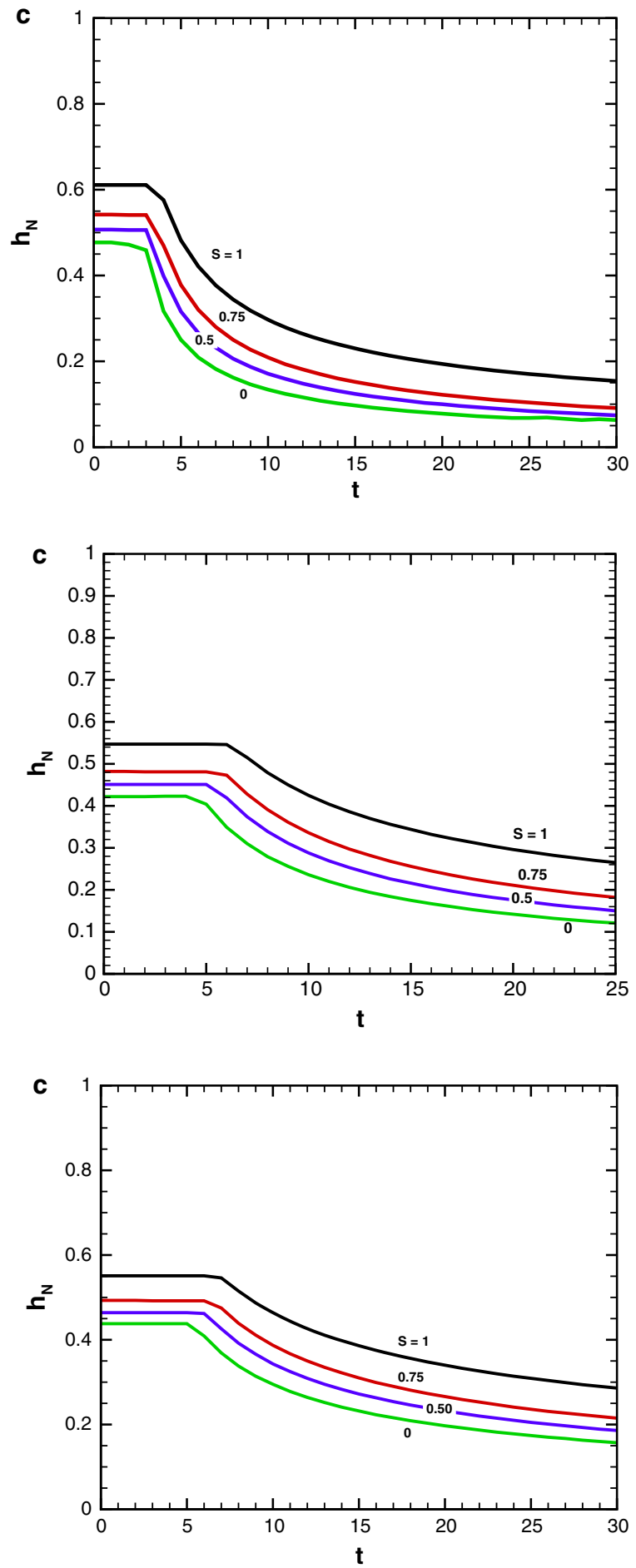